\title{
Spinal stenosis subsequent to juvenile lumbar osteochondrosis
}

\author{
Kaj Tallroth, M.D., F.I.C.A. ${ }^{1, *}$ and Dietrich Schlenzka, M.D. ${ }^{2}$ \\ ${ }^{1}$ Department of Radiology and ${ }^{2}$ Department of Orthopaedic Surgery, Orthopaedic Hospital of the Invalid Foundation, \\ Helsinki, Finland
}

\begin{abstract}
This paper describes eight patients with spinal stenosis associated with marked osteochondrous changes in the vertebral bodies due to juvenile lumbar osteochondrosis (Scheuermann's disease). In no case was the midsagittal or interpedicular diameter of the spinal canal indicative of bony stenosis. On the other hand, in the myelograms the sagittal diameter of the dural sac was in all cases significantly narrowed, a diagnostic sign of central spinal stenosis. Therefore, myelography should always be contemplated when osteochondrous changes are present and spinal stenosis is suspected clinically regardless of whether the spinal canal diameters are normal in plain films.
\end{abstract}

Key words: Lumbar osteochondrosis - Radiology Myelography - Spinal stenosis

Narrowing of the lumbar spinal canal can be classified by the constituents of the wall (bone or soft tissue), the localization of the stenosis (central or lateral), or the etiology. The most common etiologic type is acquired spinal stenosis which includes such conditions as trauma, severe kyphosis or scoliosis, spondylolisthesis, Paget's disease, tabetic osteoarthropathy and acromegaly as well as degencrative spondylosis and osteoarthritis with osteophytes and hyperostosis [2, 10, 11, 15, 19]. As far as we have learned from literature surveys, juvenile lumbar osteochondrosis has not been documented as a cause of or predisposing factor in developmental spinal stenosis. In this paper we present eight patients with a narrowed spinal canal subsequent to juvenile lumbar osteochondrosis. Further, we discuss the difficulties associated with plain film diagnosis and the valuable role of myelography.

* Current address: Department of Radiology, University of Michigan Hospitals, Ann Arbor, MI 48109-0030, USA

Address reprint requests to: Dr. D. Schlenzka, Orthopaedic Hospital of the Invalid Foundation, Tenholantie 10, SF-00280 Helsinki, Finland

\section{Material and methods}

From April 1985 to April 1989 we performed lumbar myelography on eight patients (all male, mean age 43.4 years, range $27-51$ years) in whom the diagnosis was registered as spinal stenosis due to vertebral changes typical of juvenile lumbar osteochondrosis. The indications for myelography were sciatic syndrome in two patients and chronic lumbar pain in six. Spinal stenosis was suspected in five patients as a result of clinical examination and a history of bilateral, intermittent pain and claudication without signs of arterial insufficiency. After retrospective review of the plain radiographs and myelograms, the findings were classified and recorded.

We assessed the number of vertebrae affected by osteochondrosis and showing elongated and wedge-shaped bodies and endplate depressions (Schmorl's nodes) as well as signs of central spinal stenosis. This assessment included measurement of the midsagittal diameter using the method originally described by Eisenstein $[7$, 8]. According to his experimental work, the posterior limit of the spinal canal from the first to the fourth lumbar vertebrae is located at the level of the cephalad half of the vertebral body on a line joining the apices of the superior and inferior articular facets. For the fifth lumbar vertebra, the posterior limit of the spinal canal is located just anterior to a well-demarcated radiolucent area in the spinous process. The interpedicular diameter is measured as the distance between the oval pedicles in the frontal radiograph. In this study, we noted common features of spinal stenosis: high, narrowed intervertebral windows; sagittally oriented, long intervertebral joints; and thickened, enlarged laminae. The diameters were measured in millimeters and adjusted by a geometrical magnification factor of 0.82 . A midsagittal diameter $\leqq 11 \mathrm{~mm}$ or an interpedicular diameter $\leqq 18 \mathrm{~mm}$ was regarded as indicative of spinal stenosis $[8,9]$.

The myelograms were all performed with a nonionic, watersoluble contrast medium (metrizamide or iohexol). The radiographic criterion for central spinal stenosis was a sagittal diameter of the dura less than $10.5 \mathrm{~mm}$ in an extended position [17]. Furthermore, the coexistence of bilateral indentation of the dura and intradural redundant nerve roots (serpentine filling defects) was documented $[13,16]$.

\section{Results}

All eight patients had five lumbar vertebrae. Typical features of osteochondrosis could be noted in five vertebrae in one patient, in four vertebrae in four patients, and 


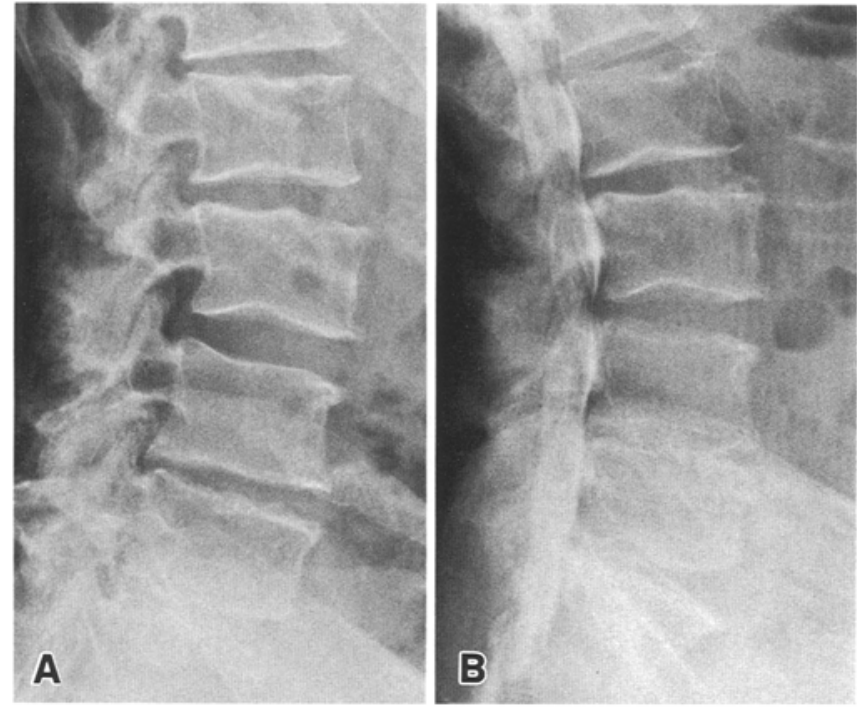

Fig. 1. A The lumbar vertebrae are sagittally elongated and show end-plate depressions typical of lumbar osteochondrosis. The small osteophytes and narrowed discs indicate a general spondylosis in this 49-year-old man. B A metrizamide myelogram shows compression of the subarachnoid space at several disc spaces

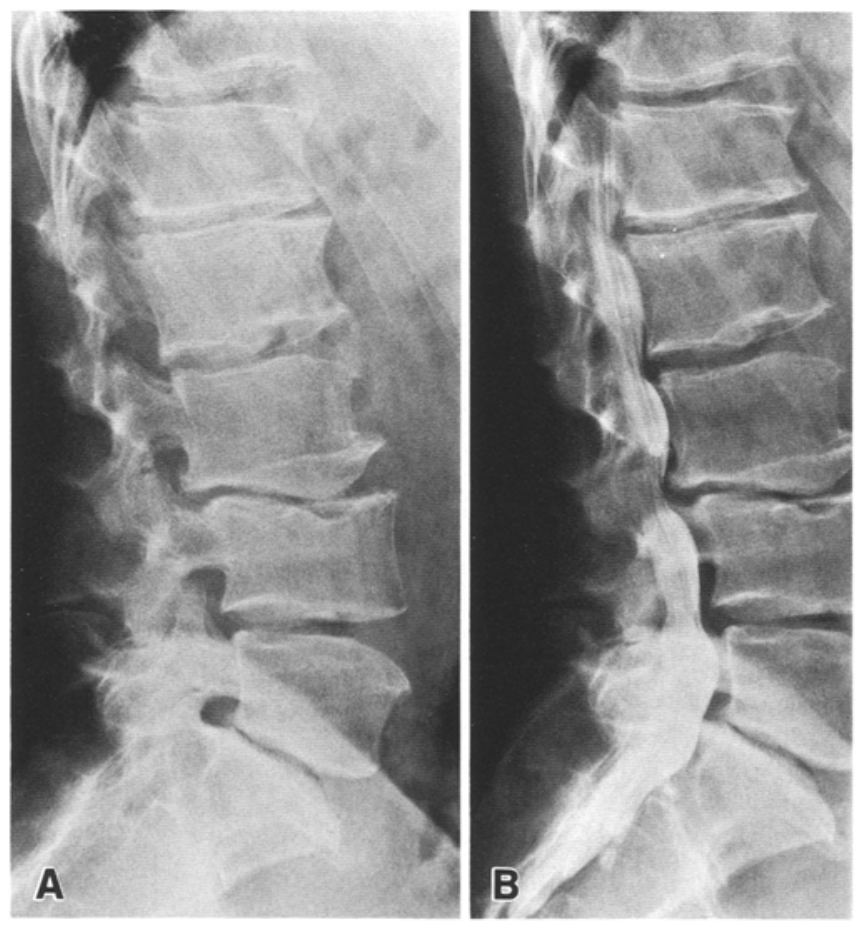

Fig. 2. A All vertebral bodies are deformed by juvenile osteochondrosis in this 41-year-old man. The bodies have large end-plate depressions, L1-2 bodies are wedge-shaped, and L1-4 are elongated. The retrolisthesis of L2-4 is due to osteoarthrosis and incongruence of the intervertebral joints. B The retrolisthesis and spinal stenosis are elegantly portrayed on the Iohexol myelogram

in three vertebrae in three patients (Fig. 1). The smallest midsagittal diameter of the central spinal canal assessed from the lateral plain film ranged from 12 to $19 \mathrm{~mm}$. The interpedicular distance in the frontal plain film ranged from 19 to $26 \mathrm{~mm}$. In two of the eight patients
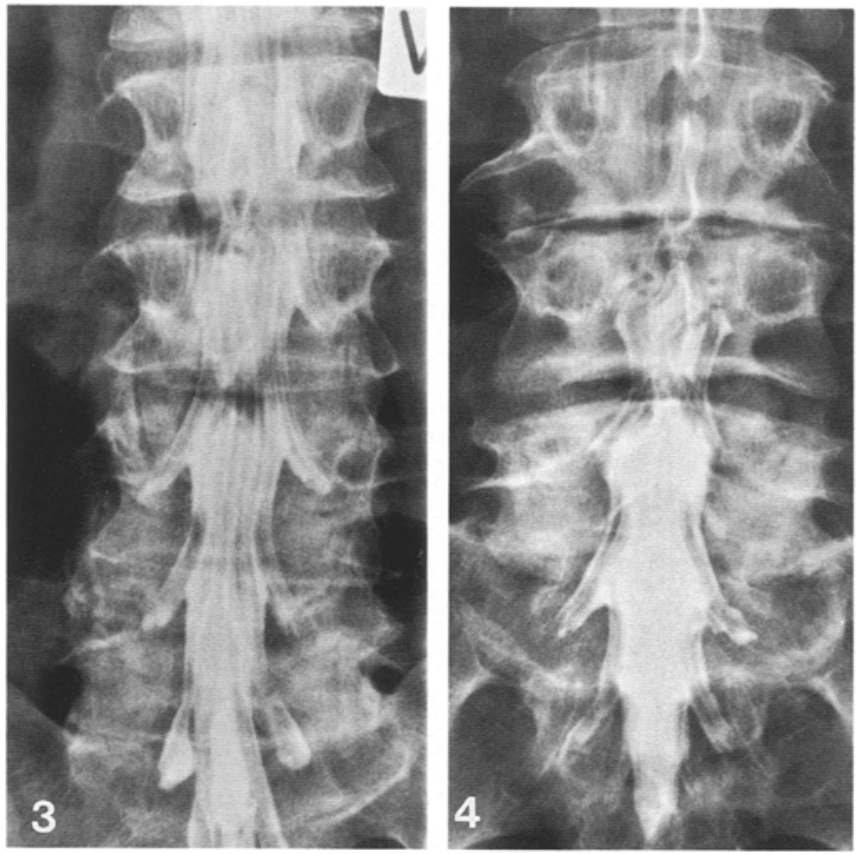

Fig. 3. Frontal myelogram demonstrating multiple bilateral indentations in a 36-year-old patient with severe symptoms of spinal stenosis

Fig. 4. This frontal myelogram shows tortuous defects in the contrast column. These are redundant nerve roots and are localized above the stenotic dise interspaces

the frontal radiograph showed at least two of the signs often related to stenosis, namely, narrow intervertebral windows, sagittally-oriented intervertebral joints, or enlarged laminae. In four patients the posterior elements of the vertebrae did not show any signs of central or lateral spinal stenosis. Degenerative osteoarthritis and incongruence in the intervertebral joints occurred in three patients at the three most caudad levels (Fig. 2).

Myelography demonstrated an obvious central spinal stenosis in all patients. The smallest sagittal diameter of the dura ranged from 5 to $9 \mathrm{~mm}$. In two patients the stenosis involved four vertebral levels; in four, three levels; and in two, two levels. In all cases the narrowest space was at an intervertebral disc level. Four patients' frontal myelograms demonstrated hourglass constrictions of the contrast medium column at several disc lev els (Fig. 3). One of these three had, in addition, redundant nerve roots, a manifestation of spinal stenosis (Fig. 4).

\section{Discussion}

In 1957 Edgren and Vainio [6] described a series of patients with atypical Scheuermann's disease with osteochondrotic changes in the thoracolumbar and lumbar regions. They named this clinico-radiographic entity "osteochondrosis juvenilis lumbalis". This thoracolumbar and lumbar type of juvenile osteochondrosis is typified by the almost constant presence of severe pain during adolescence, which distinguishes it from the classic Scheuermann's disease of the thoracic region in which 
pain is rare and mild $[1,4]$. Excessive mechanical load applied to the growing spine was identified as an important etiological factor causing such changes of the vertebrae [3, 12]. Green et al. [12] considered these changes abnormalities of a nonprogressive nature. Stoddard and Osborne [18], however, reported a significantly higher incidence of spondylotic changes and backache in patients who had previous lumbar osteochondrosis than in those who did not.

There are reports in the literature on the extremely rare condition of compression of the myelon in the thoracic region in classic Scheuermann's disease, either due to angular deformity alone or associated with thoracic herniated disc [5, 14]. However, as far as we know, lumbar spinal stenosis has not been cited as a late complication of lumbar osteochondrosis.

All patients included in this series demonstrated significant narrowing of the sagittal diameter of the dural sac at myelography, whereas the measurements on plain radiographs were not indicative of bony stenosis. This discrepancy illustrates the importance of using an additional imaging modality for the definitive diagnosis. We chose myelography instead of computed tomography because of the tendency of spinal stenosis to involve multiple levels of the lumbar spine. In many centers, magnetic resonance imaging has already supplanted both myelography and computed tomography in the evaluation of certain conditions of the spine.

In all of our patients maximum narrowing occurred at the level of the intervertebral disc and was secondary to the combined effects of posterior disc protusion and posterior prominence of the vertebral end-plates. We considered the end-plate deformity a sequel of juvenile lumbar osteochondrosis. Because the mean age of the patients was 43.4 years, it is probable that the original abnormality was accentuated by degenerative osteophyte formation. Because of the prominence of the endplates, the posterior surfaces of the vertebral bodies were concave. Thus, it is quite logical that the mid-sagittal diameter measured between the end-plates was within normal limits in all cases.

Our observation supports the opinion that there are marked differences between the thoracic and the lumbar types of juvenile osteochondrosis. Lumbar spinal stenosis should be considered in young adults with signs of osteochondrosis of the lumbar spine.

\section{References}

1. Ascani E, Montenaro A (1985) Scheuermann's disease. In: Bradford DS, Hensinger RM (eds) The pediatric spine, 1 st edn. Thieme, New York, p 309

2. Babin $E$ (1980) Radiology of the narrow lumbar canal. In: Wackenheim A, Babib E (eds) The narrow lumbar canal. Springer, Berlin Heidelberg New York, p 6

3. Blumenthal SL, Roach J, Herring IA (1987) Lumbar Scheuermann's. A clinical series and classification. Spine 12:929

4. Bradford DS (1987) Juvenile kyphosis. In: Bradford DS, Lonstein JE, Moe JH, Ogilvie JW, Winter RB (eds) Moe's textbook of scoliosis and other spinal deformities, 2 nd edn. Saunders, Philadelphia, p 351

5. Bradford DS, Garcia A (1969) Neurological complication in Scheuermann's disease. J Bone Joint Surg [Am] $51: 567$

6. Edgren W, Vainio S (1957) Osteochondrosis juvenilis lumbalis. Acta Chir Scand [Suppl] 227:18

7. Eisenstein S (1976) Measurements of the lumbar spinal canal in 2 racial groups. Clin Orthop 115:42

8. Eisenstein S (1977) The morphometry and pathological anatomy of the lumbar spine in South African negros and caucasoids with specific reference to spinal stenosis. J Bone Joint Surg [Br] $59: 173$

9. Epstein BS, Epstein JA, Jones MD (1977) Lumbar spinal stenosis. Radiol Clin North Am 15:227

10. Epstein JA, Epstein BS, Lavine L (1962) Nerve root compression associated with narrowing of the lumbar spinal canal. J Neurol Neurosurg Psychiatry 25:165

11. Epstein N, Whelan M, Benjamin V (1982) Acromegaly and spinal stenosis. J Neurosurg 56:145

12. Greene TL, Hensinger RM, Hunter LY (1985) Back pain and vertebrae changes simulating Scheuermann's disease. J Pediatr Orthop 5:1

13. Hacker DA, Latchaw RE, Yock DH Jr, Ghoshajura K, Gold LHA (1982) Redundant lumbar nerve root syndrome: myelographic features. Radiology 143:457

14. Lonstein JE, Winter RB, Moe JH, Bradford DS, Chou SN, Pinto WC (1980) Neurological deficits secondary to spinal deformity. Spine $5: 331$

15. Nelson MA (1973) Lumbar spinal stenosis. J Bone Joint Surg [Br] 55:506

16. Shapiro R (1984) Myelography, 4th edn. Year Book Medical, Chicago, p 532

17. Sortland O, Magnaes B, Hauge T (1977) Functional myelography with metrizamide in the diagnosis of lumbar spinal stenosis. Acta Radiol [Diagn] (Stockh) [Suppl] 355:42

18. Stoddard A, Osborne JF (1979) Scheuermann's disease or spinal osteochondrosis. Its frequency and relationship with spondylosis. J Bone Joint Surg [Br] 61:56

19. Verbiest $H$ (1976) Fallacies of the present definition, nomenclature, and classification of the stenosis of the lumbar vertebral canal. Spine 1:217 